\title{
EXPLORANDO E CONSTRUINDO UM CONCEITO DE GESTÃO ESCOLAR DEMOCRÁTICA
}

\section{Ângelo Ricardo de Souza*}

RESUMO: Este artigo toma as relações entre a política, o poder e a democracia na escola pública como objeto da investigação bibliográfica. Destacando os elementos que caracterizam a gestão escolar como fenômeno político e como lócus para os processos de disputas e de dominação, este trabalho coteja as características da democracia e aponta para um conceito de gestão escolar democrática como um processo que não se resume às tomadas de decisão e que é sustentado no diálogo e na alteridade, na participação ativa dos sujeitos do universo escolar, na construção coletiva de regras e procedimentos e na constituição de canais de comunicação, de sorte a ampliar o domínio das informações a todas as pessoas que atuam na/sobre a escola.

Palavras-chave: Gestão Democrática; Gestão Escolar; Política Escolar.

\section{EXPLORING AND BUILDING A CONCEPT OF DEMOCRATIC SCHOOL MANAGEMENT}

ABSTRACT: This bibliographical research studies the relations between politics, power and democracy in public schools. It highlights the elements which characterize school management as a political phenomenon and as the locus of dispute and dominating processes. The study also evaluates the characteristics of democracy, developing a concept of democratic school management, considering it as a dialogue-oriented process, through the active participation of those with school connections, through a collective construction of rules and procedures, and through the establishment of channels of communication with a view to broaden the information domain to those in the school universe.

Keywords: Democratic Management; School Management; School Politics.

\footnotetext{
* Doutor em Educação pela Pontifícia Universidade Católica de São Paulo (PUC-SP); Professor e Pesquisador do Núcleo de Políticas Educacionais e do Programa de Pós-Graduação em Educação da Universidade Federal do Paraná (NuPE/UFPR).E-mail: angelo@ufpr.br
} 


\section{Introdução}

Este artigo discute as relações entre a política, o poder e a democracia na escola pública. Os objetivos imediatos são os de destacar os elementos atinentes à gestão escolar que lhe caracterizam como fenômeno fundamentalmente político e, como tal, como palco para os processos de disputa e de dominação. Ao discutir essa natureza política da gestão escolar, este trabalho a coteja com o universo da democracia.

A gestão escolar, pelas determinações legais, deve ser pautada pelo princípio e pelo método democráticos. Todavia, há pouca clareza sobre o que significa a tradução de um em outro, na ação concreta nas escolas públicas país afora. Nesse sentido, este trabalho se propõe levantar elementos importantes para se pensar os problemas tanto da compreensão quanto da efetivação da gestão democrática nas escolas públicas brasileiras.

No texto, em uma primeira sessão, analisam-se as relações e provocações entre o poder e a democracia. $\mathrm{Na}$ sessão seguinte, a participação, condição democrática preliminar, é colocada em questão, averiguando-se em que medida e possibilidade a participação de fato se constitui como condição democrática.

\section{Democracia e poder}

O interesse da ação política é o poder. No campo da gestão escolar, muitos são os trabalhos que estudam, descrevem, analisam ou têm em perspectiva formas de se conduzir a política escolar voltadas mais à divisão desse poder (SOUZA, 2007). O poder em questão que torna a gestão um processo político, para essa perspectiva da gestão democrática, não é a capacidade da parte de quem o controla em levar os outros sujeitos não-controladores desse poder a fazerem o que aqueles desejavam, e ainda legitimamente reconhecendo a relação de dominação, como afirma Max Weber (2004, p. 43). Assemelha-se mais ao poder decorrente da capacidade humana de agir em conjunto com outros, construindo uma vontade comum (ARENDT, 2000; BOBBIO, 2000).

Essa questão diz respeito à compreensão da natureza política da gestão escolar, pois se a política na escola representa operar a disputa com 
(grupos de) pessoas rivais em relação a diferentes compreensões, na busca pelo controle sobre a própria escola, então teremos a aproximação entre ação política e poder no sentido weberiano; mas, se a política na escola reconhece que o poder em questão decorre de um contrato firmado entre as pessoas que compõem essa instituição, e considera que o diálogo entre esses sujeitos é precondição para a sua operação, assim se terá uma ação política talvez mais democrática. Mas num ou noutro caso, se trata sempre de poder, pois a política somente existe onde há poder em questão. A forma como se lida com ele, contudo, pode demonstrar uma vocação mais ou menos democrática.

Senão vejamos o caso do pressuposto do "respeito à maioria". Basear as decisões em respeito à regra da maioria é um princípio da democracia formal, como mais adiante veremos com Bobbio. Mas isso pode representar atitude pouco democrática de fato, particularmente como realizada no mundo da democracia representativa formal. A escola, como instituição que tem a tarefa de promover o diálogo, a humanização do humano e a sua emancipação (ADORNO, 1998), ao pautar seus processos de gestão a partir sempre da lógica da maioria, corre sério risco de padronizar suas tomadas de decisão em procedimentos que podem ser mais expressão da violência do que da democracia, uma vez que a maioria, mesmo que fluida, quando ciente do controle que possui sobre as decisões, dificilmente abre mão de suas posições, mesmo tendo frageis argumentos para mantê-las, pois tem, neste caso, o principal argumento: a força. A instituição de conselhos de escola, eleições para dirigentes escolares ou outros mecanismos tidos como de gestão democrática que atuam a partir da regra da maioria, per si, portanto, não representam a essência da democracia. Se os indivíduos que compõem essas instituições não pautarem suas ações pelo diálogo e pela alteridade, pouco restará de democrático nessas ações coletivas. Diante disso, a busca da força do argumento parece ser a alternativa (HABERMAS, 1990).

A gestão democrática é aqui compreendida, então, como um processo político no qual as pessoas que atuam na/sobre a escola identificam problemas, discutem, deliberam e planejam, encaminham, acompanham, controlam e avaliam o conjunto das ações voltadas ao desenvolvimento da própria escola na busca da solução daqueles problemas. Esse processo, sustentado no diálogo, na alteridade e no reconhecimento às especificidades técnicas das diversas funções presentes 
na escola, tem como base a participação efetiva de todos os segmentos da comunidade escolar, o respeito às normas coletivamente construídas para os processos de tomada de decisões e a garantia de amplo acesso às informações aos sujeitos da escola.

Isso quer dizer que a gestão da escola pública² pode ser entendida pretensamente como um processo democrático, no qual a democracia é compreendida como princípio, posto que se tem em conta que essa é a escola financiada por todos e para atender ao interesse que é de todos; e também como método, como um processo democratizante, uma vez que a democracia é também uma ação educativa, no sentido da conformação de práticas coletivas na educação política dos sujeitos. É certo que essas ideias não expressam a realidade da gestão das escolas públicas, mas, se tomamos o conceito como hipótese ou como matriz a ser cotejada com a realidade, sua amplitude democrática pode nos ser bastante útil na observação do fenômeno. Isto é, a gestão democrática, nessa perspectiva, talvez se assemelhe a um tipo ideal (WEBER, 1992, p. 137), que pode ser utilizado como referência para a melhor compreensão da realidade empírica ${ }^{3}$.

A preocupação na construção de conceitos sobre a gestão democrática é compartilhada por outros autores, como é o caso de Licínio Lima, para quem a democratização da gestão escolar é

uma perspectiva conceptual que focaliza intervenções democraticamente referenciadas, exercidas por actores educativos e consubstanciadas em acções de (auto)governo; acções que não apenas se revelam enquanto decisões políticoadministrativas tomadas a partir de contextos organizacionais e de estruturas de poder de decisão, mas que também interferem na construção e recriação dessas estruturas e de formas mais democráticas de exercer os poderes educativos no sistema escolar, na escola, na sala de aula, etc. (LIMA, 2000, p. 19)

Para Lima, a gestão democrática é um fenômeno político, de governo, que está articulado diretamente com ações que se sustentam em métodos democráticos. Mas, mais do que isso, para o autor, não se trata apenas de ações democráticas ou de processos participativos de tomada de decisões, trata-se, antes de tudo, de ações voltadas à educação política, na medida em que são ações que criam e recriam alternativas mais democráticas no cotidiano escolar no que se refere, em especial, às relações de poder ali presentes. 
Porém, parece que há dificuldades para a constituição dessa educação política e, pior, em seu lugar parece haver a constituição de elementos de reprodução do autoritarismo pela própria educação escolar. A escola, como todas as demais instituições, está solidificada pelos mesmos princípios instituidores da sociedade, uma vez que é parte dela, instituinte dela e instituída por ela. Dessa maneira, expressa formas de manutenção e reprodução da cultura muito próximas do que acontece fora dos seus domínios. Essa contradição, de ser adaptadora e reprodutora da sociedade e, ao mesmo tempo, permitir condições de superação da sociedade pelos indivíduos, não é verdadeiramente o problema, mesmo porque o próprio ato educativo formal, como desenhado ao longo da modernidade, é um fenômeno de repetição do antigo e de construção do novo, constantemente. O problema reside nas sucessivas expressões da perversidade institucional que a escola demonstra, educando não contra, mas a favor do autoritarismo. Quando as pessoas na escola reforçam sua tradição de classificar, de enfatizar o melhor (ou de se submeter a indicar o melhor aluno para a sociedade), de hierarquizar, de recrutar forçosamente, entre outras características da sua cultura, agem de forma perversa e antagônica com as reais necessidades educativas (SANTOS GUERRA, 1994, p. 17-36). Não parece possível erradicar o autoritarismo sendo autoritário, construir o diálogo sendo demagógico, superar a violência agindo de forma preconceituosa. As pessoas na escola utilizam, muitas vezes, sua autoridade para definir o correto e o incorreto, atrelando àquele, por exemplo, a atitudes de controle e até de submissão e este, a atitudes de subversão.

As possibilidades de superação das desigualdades sociais, reproduzidas - entre outras formas - pelo sistema de ensino, são pauta de uma ação social/coletiva, por meio da qual a educação escolar busca rever seus rumos, suas organizações. Porém, certamente a face individual dessa tarefa parece ser a mais hercúlea das ações, pois demanda a autoconsciência, a emancipação de cada um dos indivíduos (ADORNO, 1998) e, uma vez que se constata que este é um mundo que é expressão do reino das necessidades, essa se torna uma tarefa ainda mais complexa.

Os/as filhos/as de famílias com frágil capital cultural, com pouco capital econômico, podem superar as desigualdades que a sociedade de classes lhes impõe e superar não apenas as dificuldades individuais, mas contribuir para superar a própria sociedade de classes? A 
escola, instrumento de reprodução, de adaptação, pode apresentar alguma alternativa de subversão na sua face de resistência? As possibilidades de responder afirmativamente a essas questões parecem estar vinculadas à construção e à efetivação nos currículos, oficiais ou não, de outra forma de se entender a democracia, bem como às formas mais democráticas de organização e gestão da escola pública.

Contudo, os mecanismos da organização escolar presentes nas suas esferas pedagógica, administrativa e institucional argúem uma igualdade formal, considerando, no sentido mais clássico, a igualdade de direitos presente na maioria das constituições do mundo ocidental. Com esse movimento, mesmo discursando muitas vezes em favor das diferenças individuais, a escola regulamenta e legitima a desigualdade social, tratando aqueles que nunca terão chance como sujeitos para os quais é necessário dar esperança.

Um teste sobre a realidade da democracia na escola e em toda a sociedade pode decorrer da seguinte pergunta:

A melhor maneira de provar em que medida a realidade de uma sociedade "democrática" está de acordo com os seus ideais não consistiria em medir as chances de acesso aos instrumentos institucionalizados de ascensão social e de salvação cultural que ela concede aos indivíduos das diferentes classes sociais? (BOURDIEU, 1998, p. 64)

Ou seja, pensar a democracia exige pensar as possibilidades reais de sua realização. Do contrário, trata-se apenas de uma democracia estética, na qual as pessoas atuam na esfera pública fazendo escolhas como uma ação que se basta em si mesma ${ }^{4}$. A democracia se faz menos nas definições formais, constitucionais, dos direitos dos indivíduos e mais pela ampliação real das condições de superação das desigualdades sociais.

É curioso que o modelo de superação das dificuldades sociais, e consequente democratização da sociedade, (quase) sempre remeta à ideia de superação individual dessas dificuldades, cujo produto esperado é a ascensão social, ou seja, a possibilidade de ter sucesso nesse mesmo mecanismo que provoca e conserva o indivíduo na condição de excluído.

Um elemento importante para discutirmos a questão da democracia é referente à relação indivíduo e coletivo. A "supremacia cega de todos os coletivos" (ADORNO, 1998, p. 85) é algo extremamente perigoso para a sobrevivência da sociedade à violência. A cultura é o que 
nos institui como indivíduos e é ela própria que nos coloca o sentimento de pertença aos grupos sociais. Esse pertencimento não precisaria concorrer contra a formação cultural do indivíduo, mas, nesta sociedade, é o que ocorre, tanto que a ideia de coletivização supera a concepção de indivíduo (ADORNO, 1998, p. 85), o que também expressa uma forma complexa de violência e de autoritarismo.

De acordo com Bobbio, a contribuição que a democracia pode dar efetivamente à superação das condições sociais é a transparência do poder, elemento este que estará presente em qualquer conceito que se tenha de democracia (BOBBIO, 2000, p. 21). A democracia, para esse autor, é algo instrumental que estabelece "um conjunto de regras de procedimento para a formação de decisões coletivas, em que está prevista e facilitada a participação mais ampla possível dos interessados" (BOBBIO, 2000, p. 22), ou ainda, “a democracia (...) é caracterizada por um conjunto de regras (primárias ou fundamentais) que estabelecem quem está autorizado a tomar as decisões coletivas e com quais procedimentos" (BOBBIO, 2000, p. 30). Isso significa que ele pensa a democracia concretamente como dada no mundo ocidental contemporâneo, ou seja, como a democracia representativa, na qual a regra da maioria é pressuposta. Essa regra é um dos aspectos que Bobbio apresenta como condições para a democracia. As outras são a exigência da participação de um número elevado de sujeitos nos processos de tomada de decisões e a garantia de que os sujeitos que são chamados a participar dos processos de tomada de decisões devem ter as condições mais próximas possíveis do ideal para tais procedimentos (BOBBIO, 2000, p. 31-32).

A democracia, para o pensador italiano, não é uma condição ideal ou de uma formação social idealmente desejada. Ela se faz presente nas relações sociais/de poder atuais como conquista de um Estado pautado pelo direito (BOBBIO, 2000, p. 23), mas que encontra enormes problemas na sua efetivação e na confirmação dos seus princípios. Uma vez que a ainda forte "presença de um poder invisível corrompe a democracia, a existência de grupos de poder que se sucedem mediante eleições livres permanece, ao menos até agora, como a única forma na qual a democracia encontrou a sua concreta atuação" (BOBBIO, 2000, p. 21).

Ademais, há algumas promessas e premissas não realizadas pela democracia que se frustraram ao longo da história. Se a democracia nasceu como a política do sujeito (TOURAINE, 1998), ou melhor, do 
indivíduo, ela hoje é a expressão dos grupos. Se a democracia moderna nasceu representativa, na qual o representante não é uma pessoa submissa a um mandato vinculado, mas se torna, uma vez eleito, representante de toda a sociedade, atualmente nada mais ausente do que esta ideia de representante de toda a coletividade, pois os representantes são cada vez mais vinculados aos pequenos grupos e estamentos que os elegeram. Se a democracia surgiu com a promessa de derrotar o poder oligárquico, desde há muito é possível verificar, no melhor estilo schumpeteriano, que a democracia não é a ausência de elites, mas a presença das elites em disputa pelo poder, pela legitimidade do voto. Se a democracia prometia ampliar a participação do cidadão na vida pública, aqui entendida como as ações do governo, atualmente talvez se tratasse da democracia se preocupar menos com a quantidade de situações em que a população vota e mais com os locais nos quais isso é possível, ou seja, a democracia não ocupou outros espaços da vida social que não o poder público. A democracia também prometia acabar com o poder invisível e instituir um regime de publicização das ações governamentais, com o intuito de controlá-las. Ao que parece, atualmente, o que se tem é o oposto: em vez de a população controlar o governo, na democracia moderna é o governo quem tem o poder de controlar o povo. E, por fim, a democracia nasceu articulada àquela questão já colocada da educação política, da educação para a cidadania, na medida em que prometia que quanto mais participativa a população pudesse ser, mais ainda ela participaria da vida política e mais se educaria sobre os seus direitos e interesses. Mas, "olhemos ao redor: nas democracias mais consolidadas assistimos ao fenômeno da apatia política, que freqüentemente chega a envolver cerca da metade dos que têm o direito ao voto" (BOBBIO, 2000, p. 45). Esses problemas no nãocumprimento das promessas da democracia (BOBBIO, 2000, p. 34-45) decorrem, ainda segundo o mesmo autor, de alguns obstáculos.

Inicialmente, Bobbio observa que a mudança da economia familiar para uma economia de mercado, contemporânea do surgimento da democracia moderna, ampliou os problemas para cuja solução o conhecimento técnico especializado é requerido. A democracia baseia-se na ideia de que "todos podem decidir sobre tudo" (BOBBIO, 2000, p. 46), mas isso nem sempre é eficaz, dadas as dimensões técnicas mencionadas.

Articulado a esse problema, o crescimento da burocracia apresenta-se como um segundo obstáculo. O autor evidencia, como já fazia 
Weber (2004), que a ampliação da democracia se deu no mesmo passo que a burocratização ${ }^{5}$. Ocorre que a burocracia, segundo Bobbio, se organiza como estrutura de poder hierarquicamente do vértice para a base e a democracia pressupõe o oposto disso. Nesse sentido é que a burocratização impediu o avanço da organização do poder na sociedade a partir da base social.

Por último, um terceiro obstáculo refere-se à constatação sobre o alargamento das demandas sociais, fruto da própria democracia, que dificulta sobremaneira a solução desses mesmos problemas sociais. O governo democrático como lugar de confluência das demandas crescentes $^{6}$ vê-se incapaz de atender a todos e tem de fazer opções, as quais geram descontentamentos, seja de quem não teve suas demandas atendidas, seja de quem, pior, teve suas demandas negadas pelo atendimento dos pedidos de outros grupos (BOBBIO, 2000, p. 46-48).

Há alguns problemas nessas avaliações de Bobbio. Inicialmente, o problema da regra da maioria ${ }^{7}$. Esse ponto, já comentado, também é abordado por Touraine, para quem a democracia não pode ser reduzida apenas ao governo da maioria (TOURAINE, 1996, p. 38). Mais que isso, a democracia é entendida por ele como "um conjunto de garantias para evitar a tomada ou manutenção do poder de determinados dirigentes contra a vontade da maioria" (TOURAINE, 1996, p. 10). A maioria da população é, então, algo que o preocupa, mas não como aquela parte que estabelece tudo a todos, incluindo a si, através de seus representantes. Não há democracia sem o respeito aos interesses da maioria, mas tampouco sem o respeito aos direitos das minorias.

Touraine é um autor que se preocupa especialmente com os lugares dos sujeitos, individual e coletivo, na sociedade e olha para a democracia como a instituição capaz de garantir tais lugares. Nesse sentido, afirma a combinação entre a unidade e a diversidade, entre a integração e a liberdade na vida social e política. E conclui que não faz sentido opor os interesses da maioria aos da minoria, no sentido de excluir uma das partes:

É preciso cessar de opor, retoricamente, o poder da maioria aos direitos das minorias. Não existe democracia se esses dois elementos não forem respeitados. A democracia é o regime em que a maioria reconhece os direitos das minorias porque aceita que a maioria de hoje venha a se tornar a minoria no dia de amanhã e ficar submetida a uma lei que representará interesses 
diferentes dos seus, mas não lhe recusará o exercício de seus direitos fundamentais. (TOURAINE, 1996, p. 29)

A democracia defendida por Touraine é uma democracia social, que se coloca "no plano dos atores sociais e não acima deles e procura estabelecer a justiça, ou seja, assegurar, antes de mais nada, o acesso dos dominados à ação, à influência e ao poder político" (TOURAINE, 1998, p. 47). Já para Bobbio, por se preocupar em pensá-la procedimentalmente, a democracia paira como um elemento universal, um conjunto de regras que a todos submete.

Seja na escola seja na sociedade observada ampliadamente, a democracia tem se organizado apenas dessa maneira formal. A democracia tem se ampliado, atingido países os mais diversos e, em certo sentido, instituições da sociedade, como a escola. Mas, via de regra, ela se efetiva como um conjunto de regras que estabelecem a lógica da representação, considerando que não é possível todos discutirem e decidirem tudo todo o tempo. Para Touraine, a democracia implica mais do que a constituição de procedimentos e instituições, com vistas a tomar decisões acerca daquilo que é de interesse coletivo. Trata-se, como vimos, mais do que métodos, são princípios e concepções que balizam os métodos:

A democracia nunca será reduzida a procedimentos, nem tampouco a instituições; mas é a força social e política que se esforça por transformar o Estado de direito em um sentido que corresponda aos interesses dos dominados, enquanto o formalismo jurídico e político a utiliza em um sentido oposto, oligárquico, impedindo a via do poder político às demandas sociais que coloquem em perigo o poder dos grupos dirigentes. O que, ainda hoje, opõe um pensamento autoritário a um pensamento democrático é que o primeiro insiste sobre a formalidade das regras jurídicas, enquanto o outro procura descobrir, atrás da formalidade do direito e da linguagem do poder, escolhas e conflitos sociais. (TOURAINE, 1996, p. 37)

Outro problema com as concepções de Bobbio diz respeito à educação política que decorreria da consolidação democrática. Se é verdade que a população (no mundo ocidental e em especial nos países europeus e da América do Norte) parece pouco disposta a ocupar seu espaço formalmente garantido de eleitores, como constata o autor, ainda assim, na longa duração, parece evidente que há sentida ampliação do 
conhecimento da população sobre seus direitos. Afinal, a diminuição do número de países nos quais ditaduras de direita ou de esquerda se faziam presentes ou mesmo de estados não-republicanos não parece ser fruto do esvaziamento dos modelos econômicos que eles defendiam ou da avaliação das classes dirigentes que já era hora de (re)constituir formas mais democráticas de governo, mas decorrem de conquistas sociais e políticas desses povos, somente possíveis a partir da ampliação dos conhecimentos acerca do poder de intervenção que a própria população tem nos rumos de uma nação. Isso é educação política que emerge da democracia vivenciada ou visualizada. E a educação política está centrada basicamente na ideia de participação.

\section{Participação}

A participação na vida política é elemento importante que se aprende na prática democrática. Seja na gestão da escola, da cidade ou do país, a participação ampliada é quase sempre defendida como condição sine qua non para a efetivação democrática. E a democracia enfronhou-se tanto na vida social que participar passou a ser quase uma regra: "Participação é hoje uma palavra-chave omnipresente nos discursos político, normativo e pedagógico" (LIMA, 2001, p. 69). Politicamente, praticamente todos os candidatos a algum cargo ou função afirmam que desejam ampliar a participação da população nos processos de tomada de decisões. Regras e normas foram constituídas para que essa participação fosse garantida. Tem se pautado nos diferentes currículos a necessidade da educação política, com ênfase na participação do cidadão nas decisões da vida política e social.

É certo que não parece haver democracia sem a participação das pessoas na gestão da coisa pública. Mas há pelo menos três aspectos importantes a se registrar acerca desse fenômeno. O primeiro diz respeito à normalização e à normatização da participação. As lutas políticas pela participação na definição dos rumos da sociedade e da escola conquistaram seus intentos, e espaços formais têm sido constituídos para garanti-la. Ocorre, porém, que por vezes a normatização desses espaços e formas de participação acabam aparelhando-a, dificultando inclusive a própria participação. O conselho de escola é um exemplo dessa situação 
(PINTO, 1994; CAMARGO, 1997; SOUZA, 2007). A participação conquistada (LIMA, 2001, p. 70) transforma-se em uma participação formal, regulada, sobre a qual é possível se ter mais controle. Se a participação emerge do reclame da população na definição e no acompanhamento das ações públicas e é demonstrada pelas formas mais imediatas e, por vezes, aguerridas, ao se promover o disciplinamento da participação da população, impedem-se as ações inusitadas, que poderiam surpreender e pressionar os governantes da coisa pública.

A normatização da participação decorre e contribui, ao mesmo tempo, para a sua mitificação. Colocar as pessoas presentes em momentos em que se evidencia a ação pública passa a ser a expressão mais acabada, juntamente com o voto, da democracia, mesmo que isso ocorra em um procedimento estritamente formal e, de fato, pouco participativo.

No contexto escolar, isso ainda toma amplitude maior, dado que o processo de regulação e organização da participação pode comprometêla, uma vez que, como observa Henry, "o envolvimento tradicional dos pais na escola ocorre através da participação dos pais em um determinado número de atividades escolares que são administradas pela própria escola, no território escolar e nos termos escolares, sem uma transferência significativa de poder" (1996, p. 7, apud SÁ, 2004).

Sá (2004), na esteira de Epstein, afirma que as famílias dos alunos querem participar da escola, ou ao menos querem ter informações em maior quantidade e melhor qualificadas sobre o andamento pedagógico e o desenvolvimento dos alunos. Os alunos também desejam que suas famílias estejam mais próximas da escola. E os dirigentes escolares e professores, por seu turno, também compartilham dessas concepções. Restaria saber como se efetiva essa participação (SÁ, 2004, p. 111). Parece-nos que há, ainda, problema maior: a compreensão do que é participar, do que significa ser parte da escola ou do processo educativo: Até que ponto a participação dos pais e alunos na definição e na avaliação dos rumos da escola é bem-aceita pelos professores e dirigentes? ${ }^{8}$. De outro lado, é importante compreender que nem sempre estar presente é a forma de participação eleita pelos pais e familiares dos alunos?.

O segundo elemento importante de se destacar refere-se justamente à não-participação, porém entendida como ação política estratégica $^{10}$. A força da tese da participação leva à incorporação desse argumento por todos os segmentos da vida social e política, incluindo 
aqui os dirigentes governamentais (e escolares) mais conservadores ou autocráticos, a princípio contrários à participação. Isso se dá pelas dificuldades de quaisquer pessoas se manterem à margem dos rumos políticos balizados pelos princípios (como a democracia e a participação) adotados pela sociedade. Em reação às políticas adotadas por determinados governantes, não é incomum encontrar movimentos de rejeição à participação nas decisões (movimentos pelo voto nulo são exemplo disso).

O último aspecto se relaciona menos com a participação, mas mais com a associação entre democracia e participação nos processos de tomada de decisões. Vimos, com Lima, que a participação é um discurso onipresente. Mas o é na defesa dela apenas nas tomadas de decisões ${ }^{11}$. Contudo, se tomamos o conceito de gestão democrática há pouco mencionado, veremos que a gestão (da escola) pública é mais do que tomar decisões. Implica identificar problemas, acompanhar ações, controlar e fiscalizar, avaliar resultados. Se se trata de democratizar a gestão (da escola) pública, e isso pressupõe a ampliação da participação das pessoas nessa gestão, isso significa que a participação não pode se resumir aos processos de tomada de decisões. Nesse sentido, a participação democrática pressupõe uma ação reguladora, fiscalizadora, avaliadora, além de decisória sobre os rumos da vida política e social das instituições (escolares) e da sociedade. Mas a participação só é efetiva quando as pessoas que são chamadas a participar são colocadas em condições adequadas para tal (BOBBIO, 2000), pois não parece possível um sujeito participante avaliar o trabalho desenvolvido na escola se não tem acesso às informações que lhe permitam produzir tal avaliação.

Assim, situações de participação normatizadas em excesso, de maneira a limitarem o direito de manifestação das pessoas, ou nas quais não se encontrem as condições mínimas para a efetivação da ação política coletiva, podem estar direcionadas com vistas a "outras lógicas mais orientadas para a legitimação da organização escolar” (SÁ, 2004, p. 139) ou para o chancelamento de decisões já tomadas pelo grupo dirigente e/ou hegemônico na escola.

A análise sobre a democratização da organização e da gestão escolar não pode, de qualquer jeito, estar desarticulada da compreensão sobre as diferentes formas e razões e instâncias da participação e nãoparticipação das pessoas de todos os segmentos. É certo que a 
participação, per si, não garante a democracia, ela depende das formas participativas mais dialogadas e que garantam o "registro polifônico" (SÁ, 2004, p. 494) de todos os sujeitos que agem na/sobre a escola cotidianamente, através dos diversos instrumentos e processos da gestão escolar.

\section{Notas finais}

Este trabalho emergiu de várias necessidades teóricas. As principais decorrem do reconhecimento de que a pesquisa no campo da gestão escolar/educacional carece de uma discussão conceitual mais aprofundada sobre a gestão democrática (SOUZA, 2007) e de operar com esses conceitos de maneira menos normativa (SOUZA, 2006), ainda que parte do compromisso social do pesquisador resida justamente em apontar alternativas, mas parece mesmo necessário buscar tomar a teoria como hipótese (BRANDÃO, 2002). Assim, o cotejamento entre a realidade das escolas/sistemas de ensino com um conceito de gestão democrática, ou com aspectos da participação, ou ainda com elementos contraditórios das formas mais coletivas de gestão, pode ampliar as possibilidades de leitura das experiências concretas de democratização da organização e gestão escolar/educacional.

Este texto, ao articular a escola pública com a política, o poder e a democracia, identificou elementos que possibilitaram a construção de um conceito de gestão escolar democrática, reconhecendo-a como um processo político que é mais amplo do que apenas as tomadas de decisão e que é sustentado no diálogo e na alteridade, na participação ativa dos sujeitos do universo escolar, na construção coletiva de regras e procedimentos e na constituição de canais de comunicação, de sorte a ampliar o domínio das informações a todas as pessoas que atuam na/sobre a escola.

Todavia, não há um conceito único de gestão democrática, seguramente. Aspectos apontados pelas teorias da democracia, e discutidos neste texto, podem nos servir como norte, como um tipo desejado para a organização escolar, mas temos também o dever, como educadores e pesquisadores, de operar com os conceitos, colocando-os a serviço do questionamento da realidade e da própria teoria. 
Essa face pedagógica e política das discussões sobre a gestão democrática obrigam-nos a perceber que aquela participação política ativa, ainda que garantida pelos instrumentos organizacionais e legais escolares e dos sistemas de ensino, não se efetiva apenas pela existência desses instrumentos, uma vez que estes (conselhos, eleições, associações de pais, grêmios estudantis), isoladamente, não se fazem suficientes para a implementação da gestão democrática. Eles a auxiliam, seguramente, mas podem mesmo se tornar aparelhos burocratizantes e pouco democráticos. O seu potencial só se confirma quando as pessoas do universo escolar tomam a democracia e o diálogo como princípio não apenas das suas relações na escola, mas como um fundamento da vida, em todas as esferas da sociedade, e conseguem transpor a esfera do desejado, implementando o princípio, transformando-o em método ou, pelo menos, em agenda, tanto na organização da educação/escola quanto na pesquisa, na medida em que as escolas (como instituições destinadas à formação humana) e as pesquisas sobre a gestão escolar têm o dever de colocar em pauta os problemas e as alternativas de enfrentamento a esses problemas organizacionais e políticos, histórica e contemporaneamente.

\section{Referências}

ABRAHAMSSON, B. The logic of organizations. London: Sage Publications, 1993.

ADORNO, T. Educación e Emancipación. Madri: Morata, 1998.

ARENDT, H. $A$ condição humana. 10 ed. Trad. Roberto Raposo. Rio de Janeiro: Forense Universitária, 2000.

BOBBIO, N; MATTEUCCI, N.; PASQUINO, G. Dicionário de Política. Brasília: Editora UnB, 1992.

BOBBIO, N. O futuro da democracia. Trad. Marco Aurélio Nogueira. São Paulo: Paz e Terra, 2000.

BOURDIEU, P. Escritos de educação. Org. Maria Alice Nogueira e Afrânio Catani. Petrópolis: Vozes, 1998.

BRANDÃO, Z. Pesquisa em Educaşão: conversas com pós-graduandos. Rio de Janeiro: Editora PUC-RJ; São Paulo: Loyola, 2002.

CAMARGO, R. B. Gestão democrática e nova qualidade de ensino: o conselho de escola e o projeto de interdisciplinaridade nas escolas municipais da cidade de São Paulo (19891992). Tese (Doutorado em Educação). São Paulo: USP, 1997.

GUTIERREZ, G. L.; CATANI, A. M. Participação e gestão escolar: conceitos e potencialidades. In FERREIRA, N. S. C. (Org.). Gestão democrática da educação: atuais tendências, novos desafios. São Paulo: Cortez, 2000.

HABERMAS, J. Soberania popular como procedimento. Novos estudos Cebrap. São Paulo. n. 26, p. 100-113, março 1990. 
LIMA, L. Organização Escolar e democracia radical: Paulo Freire e a governação democrática da escola pública. São Paulo: Cortez, 2000.

LIMA, L. A escola como organização educativa. São Paulo: Cortez, 2001.

PINTO, J. M. Administração e liberdade: um estudo do conselho de escola à luz da ação comunicativa de Jürgen Habermas. Tese (Doutorado em Educação). Campinas: Unicamp, 1994.

POPKEWITZ, T. S. Reform as the social administration of the child: Globalization of knowledge and power. BURBULES, N; TORRES, C. (Org.). Globalization and Educational Policy. Nova York: Routledge, 2000. p. 157-186.

SÁ, V. A participação dos pais na escola pública portuguesa: uma abordagem sociológica e organizacional. Braga, Portugal: IEP-Universidade do Minho, 2004.

SANTOS GUERRA, M. A. Entre bastidores: el lado oculto de la organización escolar. Málaga: Aljibe, 1994.

SANTOS GUERRA, M. A. La escuela que aprende. Madri: Morata, 2000.

SCHUMPETER, J. A. Capitalismo, Socialismo e Democracia. Rio de Janeiro: Zahar, 1984.

SOUZA, A. R. Os caminhos da produção científica sobre a gestão escolar no Brasil. Revista Brasileira de Politica e Administração da Educação. v. 22, n. 1, p. 13-40, jan-jun/2006. SOUZA, A. R. Perfil da Gestão da Escola no Brasil. Tese (Doutorado em Educação). São Paulo: PUC-SP, 2007.

TOURAINE, A. O que é democracia? Trad. Guilherme João de Freitas Teixeira. Petrópolis: Vozes, 1996.

TOURAINE, A. Igualdade e diversidade: o sujeito democrático. Trad. Modesto Florenzano. Bauru: Edusc, 1998.

WEBER, M. Ciência e Política: duas vocações. São Paulo: Cultrix, 1970.

WEBER, M. Metodologia das ciências sociais (Parte 1). Trad. Augustin Wernet. São Paulo: Cortez, 1992.

WEBER, M. Economia y sociedad: esbozo de sociologia comprensiva. Trad. José Medina Echavarría, Juan Roura Parella, Eugenio Ímaz, Eduardo Garcia Máynez e José Ferrater Mora. México: FCE, 2004.

\section{Notas}

1 "Por política entenderemos (...) o conjunto dos esforços feitos com vistas a participar do poder ou a influenciar a divisão do poder. (...). Quando de uma questão se diz que é 'política', quando se diz de um ministro ou funcionário que são 'políticos', quando se diz de uma decisão que foi determinada pela 'política', é preciso entender, no primeiro caso, que os interesses de divisão, conservação ou transferência do poder são fatores essenciais para que se possa esclarecer aquela questão; no segundo caso, impõe-se entender que aqueles mesmos fatores condicionam a esfera de atividade do funcionário em sua causa, assim como, no último caso, determinam a decisão" (MAX WEBER, 1970, p. 56).

${ }^{2}$ Sabidamente, a gestão da escola privada pauta-se por outros princípios e métodos e não é objeto deste trabalho.

${ }^{3}$ Trata-se de um conceito projetivo, isto é, que talvez nem possa ser posto à prova de forma imediata. Ou ainda, esse conceito se parece com uma espécie de tipo ideal 
weberiano, que procura incorporar as diferentes características de dado fenômeno, levando-as ao limite, ao ponto de se constituir em uma descrição de um tipo que não existe empiricamente (MAX WEBER, 1992). Esse conceito de gestão democrática não corresponde, portanto, a nenhuma experiência objetiva de democratização da organização escolar, mas estabelece os elementos mais agudos sobre sua própria concepção, de sorte que se possa cotejá-lo com a realidade das escolas, na busca da percepção acerca da proximidade ou do distanciamento da escola desse tipo ideal.

${ }^{4}$ Para uma compreensão mais ampliada e aprofundada, ver a discussão sobre a democracia como design em Thomas S. Popkewitz (2000).

${ }^{5}$ Em que pese o fato de que também parece haver um caminho inverso, da democratização para a burocratização:"O sufrágio universal e o crescimento de instituições de partidos políticos de massa, ambos os quais associados com direitos gerais de votação, são fatores de grande importância para o espalhamento da burocracia" (BENGT ABRAHAMSSON, 1993, p. 38).

${ }^{6}$ Crescentes menos porque os problemas crescem e mais porque a democracia cresce, permitindo maior expressão sobre esses problemas.

${ }^{7}$ Por pensar a democracia procedimentalmente, Bobbio tende a superestimar o poder da maioria. Contudo, ele mesmo reconhece que "nenhuma decisão tomada por maioria deve limitar os direitos da minoria, de um modo especial o direito de tornar-se maioria, em paridade de condições" (N. BOBBIO et al., 1992, p. 327).

${ }^{8}$ Gutierrez e Catani (2000, p. 72) relatam experiência de debates com dirigentes escolares e destacam a compreensão que eles têm da participação dos familiares dos alunos na escola: "uma diretora de escola pediu a palavra e fez um longo elogio à participação, apenas com uma ressalva: os pais analfabetos não poderiam opinar sobre a alfabetização dos filhos já que eles mesmos não eram alfabetizados. Complementando, outra colega manifestou a confiança em que cada um poderia participar a partir da sua própria experiência, ou seja, uma mãe que fosse faxineira poderia participar ajudando na limpeza da escola, e assim por diante...".

'Virgínio Sá comenta a situação de que é bastante presente para os pais e familiares dos alunos a concepção de que a melhor forma de eles participarem da escola é simplesmente acompanhando a distância, em casa, o andamento acadêmico do aluno/filho, pois se a presença dos pais é requerida na escola, pela sua forma mais convencional e tradicional de ver os papéis institucionais da escola e da família, é porque algo de errado aconteceu: certamente são chamados para resolver algum problema afeto à criança. Isso conforma uma prática de pequena participação desse segmento, confirmada pelo mesmo autor em pesquisa empírica publicada em 2004, que afirma que os pais e familiares dos alunos veem como principais razões para a não-participação na vida da escola a falta de tradição participativa dos pais, horários inadequados para as reuniões e atendimentos, o desconhecimento dos direitos e deveres pelos próprios pais e o fato de eles não se sentirem muito à vontade na escola (Virgínio SÁ, 2004, p. 402).

${ }^{10}$ Há uma longa relação de motivos para a não-participação que vão desde o simples desinteresse até os incômodos provocados pelas consequências da participação. Lima (2001, p. 81-92) faz um aprofundado estudo sobre esses aspectos, bem como sobre os 
mitos que cercam a participação. Mas aqui trata-se de enfatizar a não-participação como um aspecto político ativo, intencional.

${ }^{11}$ Isso também é explícito em Bobbio (2000) e Touraine (1996; 1998).

Recebido: $13 / 05 / 08$

Aprovado: 13/07/09

Contato:

Universidade Federal do Paraná

Setor de Educação

Departamento de Planejamento de Administração Escolar Rua General Carneiro, 460 - $4^{\circ}$ andar - sala 407/C - Centro

Curitiba - PR

CEP 80060-150 